\title{
Concepções sobre Criminalidade e Modelos de Policiamento ${ }^{1}$
}

Concepts on criminality and policing models

Resumo: Podem-se conceber duas perspectivas teóricas básicas para explicar a criminalidade: a culturalista e a racionalista. Da primeira derivam políticas públicas destinadas a reduzir a criminalidade através de uma atuação sobre a desorganização social. Na segunda, privilegia-se uma estratégia segundo a qual o principal papel do Estado é dissuadir o criminoso da prática delituosa. Este trabalho revisa a literatura, evidenciando mitos sobre o crime e a atividade policial. São discutidos dois modelos de policiamento: um mais tradicional e reativo, e outro mais preventivo, procurando-se mostrar que o racionalismo dá maior suporte teórico a políticas de segurança pública que valorizam a promoção da cidadania.

Palavras-Chave: Segurança pública, policiamento, cidadania, violência urbana.

Abstract: We can conceive two basic theoretical perspectives to explain criminality: the culturalist and the rationalist. From the first one derives public policies aimed to decrease criminality through actions on the social disorganization. The second one emphasizes a strategy in which the main role of the state is to dissuade the offender of the criminal practice. This paper reviews the literature, making evident several myths concerning the crime and the activity of the police. Two models of police action, one more traditional and reactive and the other more preventive, will be discussed, in an attempt to show that rationalism gives more theoretical support to public safety policies that value the promotion of a sense of citizenship.

Key Words: Public safety, policing, citizenship, urban violence.

\section{Marco Antônio de Azevedo}

Psicólogo pela PUC Minas; doutorando em Clência da Informação, Mestre em Administração (organizações e RH), especialista em Criminalidade e Segurança Pública pela UFMG e professoradjunto do Instituto de Psicologia da PUC Minas.

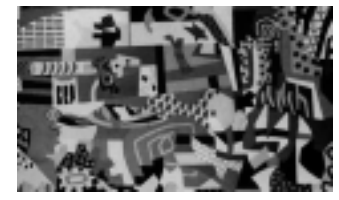

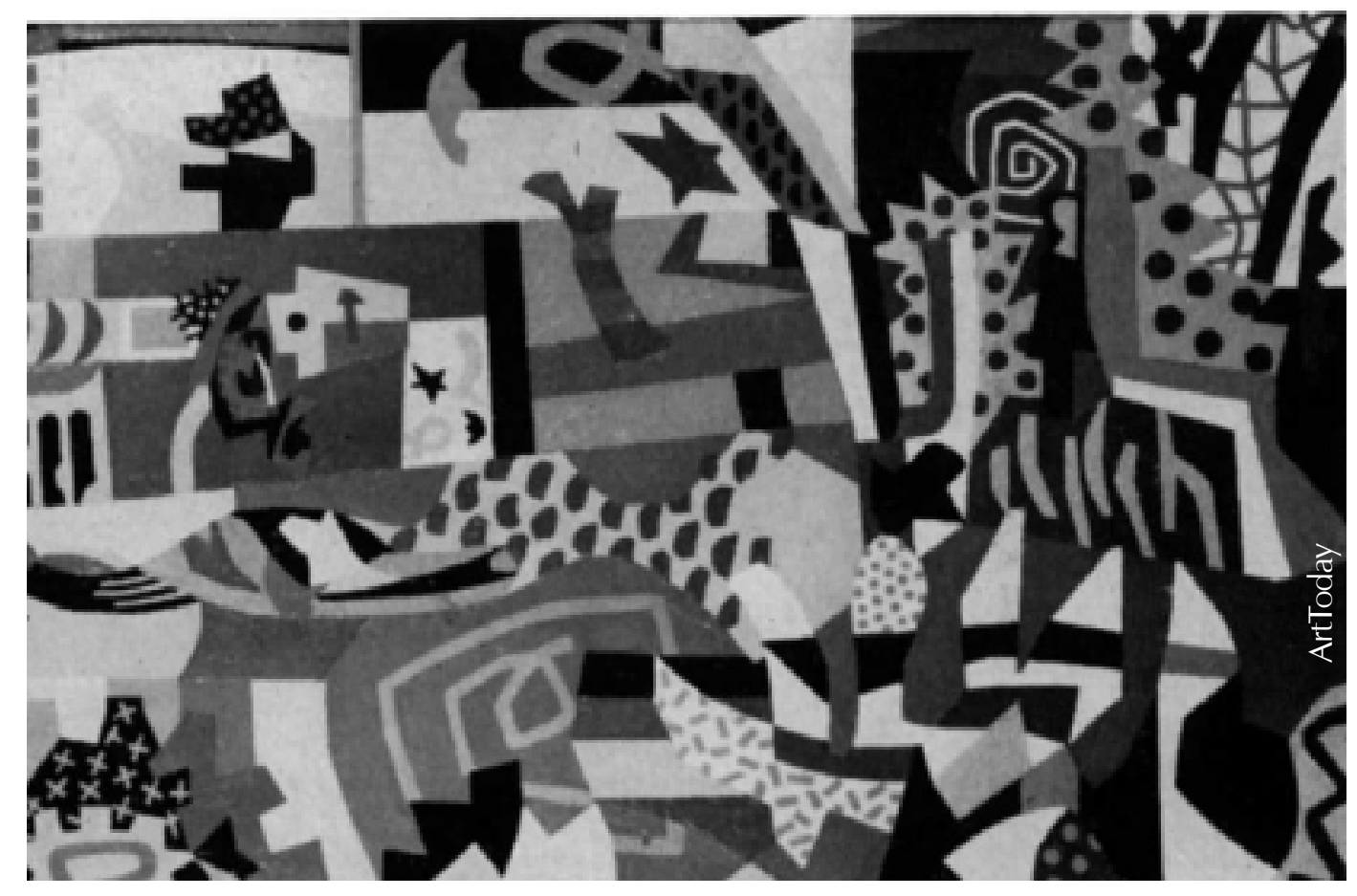

Este trabalho representa uma tentativa de sistematizar um conjunto de idéias baseadas em estudos sobre a criminalidade, os criminosos, o policiamento e a segurança pública. Procura-se defender a idéia de uma polícia comunitária, verificar as teorias sobre a criminalidade que podem the dar sustentação e, também, fazer algumas observações particularmente importantes para a prática dos psicólogos, sobre a personalidade (não necessariamente doentia) daqueles que cometem os chamados crimes ordinários ou rotineiros, com base na teoria dos rótulos e das oportunidades e no conceito de "carreira desviante".

O crescimento da criminalidade violenta nas duas últimas décadas, principalmente na América Latina, 
é um fato incontestável. Nossas taxas são duas vezes maiores que a média mundial e, no continente, Brasil, México e Colômbia são os países mais violentos. Constata-se também que aumentaram a arbitrariedade, o abuso de força e a corrupção por parte dos policiais, bem como a sensação de insegurança e de temor ao crime entre a população.

No Brasil, a gravidade, as dimensões e a natureza do problema da criminalidade, da violência e da segurança pública suscitam uma série de discussões, muitas vezes demasiadamente apaixonadas, entre as quais salientamos a da necessidade de reforma institucional do sistema policial, estando na pauta do dia a defesa, freqüentemente demagógica por parte de alguns políticos, da unificação das polícias.

Duas outras facetas importantes do problema são a desinformação e a mistificação do fenômeno em si e, principalmente, da personalidade dos criminosos, o que só faz aumentar o temor do crime, comprometendo nossa capacidade de enfrentá-lo mais racional e eficientemente. Por exemplo, os que defendem que é preciso armar a polícia partem do pressuposto de que os criminosos são muito bem equipados, desconhecendo que a esmagadora maioria dos crimes é praticada com auxílio de armas muito simples.

Beato Filho (s/d) mostra que os sistemas de informações e dados estatísticos sobre as ocorrências e sua localização espacial (geoprocessamento) são indispensáveis para identificar padrões de criminalidade que, por sua vez, permitem uma avaliação mais adequada das percepções sociais (medo) da violência, conferem mais eficiência às operações de policiamento, servem para prestar contas à comunidade, identificar os perfis dos agressores, avaliar a incidência sobre diferentes grupos sociais, o relacionamento entre agressor e vítima e chances de punição. $\bigcirc$ autor observa também que não é possível falar em um "número real de crimes", pois não se pode esquecer que a realidade empírica é socialmente construída.

De acordo com Beato Filho et al (2000), Minas Gerais, por exemplo, "tem assistido a um significativo aumento de suas taxas de criminalidade violenta". Em 1986, tínhamos uma taxa de 98 crimes por 100.000 habitantes; em 1997, essa taxa dobrou para 193 por 100.000 habitantes. Em termos absolutos, saltamos de 14.122 ocorrências para 32.477. No entanto, Belo Horizonte, a capital do Estado, não figura entre as 20 cidades mais violentas do Brasil.

Os crimes contra o patrimônio são os principais responsáveis por esse crescimento e muitas das ocorrências registradas pelas estatísticas oficiais foram praticadas por uma só pessoa. Assim, temos muito menos criminosos do que infrações, pois o desviante comete vários crimes durante sua carreira. Coletando dados, recentemente, para uma pesquisa sobre "carreira desviante", tivemos a oportunidade de entrevistar um jovem detento que, foragido por seis meses da Justiça, praticou nada menos que oito assaltos a empresas nesse curto espaço de tempo.

A violência traz pesados prejuízos ao País: avalia-se que gastamos cerca de $12 \%$ de nosso PIB no combate à criminalidade; enfrentamos a fuga de investimentos, pois as empresas estrangeiras avaliam os riscos antes de se instalarem aqui, gastos públicos, descrédito nas relações entre a população e as autoridades e muitos outros problemas. As comunidades vitimadas também têm prejuízos, como queda no valor dos imóveis, limitações de transporte, desaparecimento dos serviços de saúde e assistência social, deterioração do ambiente físico, quebra de confiança e medo entre vizinhos, perda de capital social e danos na convivência. De modo geral, a violência deixa os lugares pobres ainda mais pobres.

Como conseqüência da situação, a imprensa e a população reivindicam constantemente mais policiais nas ruas e alguns governos fazem investimentos em viaturas, armamentos, tecnologia e aumentam o efetivo policial, sem contudo obter resultados sobre as taxas de criminalidade violenta. Silva Filho, citado por Gontijo (2000, p. 47), afirma que "o problema de segurança pública não se resolve apenas com ações policiais" e apresenta o caso do governo do Estado do Rio de Janeiro que, "em 1987, efetuou maciço investimento nas polícias civil e militar, incluindo também aumento de efetivo, como proposta para a solução dos problemas de criminalidade", mas não conseguiu reduzir as taxas que, ao contrário, continuaram subindo. ${ }^{3}$

Autores americanos, como Bayley (1994), também se opõem às propostas de aumento de verbas e de investimentos financeiros e materiais como solução isolada para a ineficiência policial e vêem no "modelo operacional" adotado, que se caracteriza por uma visão limitada da atividade criminosa, o principal problema.

De fato, as sociedades contemporâneas se tornaram mais complexas e o trabalho da polícia também seguiu essa tendência, exigindo reestruturação. Trata-se de promover o equilíbrio entre dois objetivos fundamentais, porém antagônicos: assegurar a paz e a ordem na comunidade e respeitar os direitos fundamentais dos cidadãos, sobretudo os mais pobres. A questão é: como fazer isso?

Na perspectiva que aqui se procura explorar e desenvolver, entende-se que há uma crise de saber nas organizações policiais e, particularmente, no campo do policiamento ostensivo. Um longo tempo
1 Trabalho apresentado como tema livere em mesa-redonda sobre "Violência e Sociedade" no VIII Colóquio Internacional de Sociologia Clínica e Psicossociologia - UFMG julho de 2001.

2 Embora a mudança da legislação tenha produzido avanços no campo da violência doméstica, os dados da América Latina são alarmantes: $26 \%$ das chilenas e 36\% das haitianas já foram vítimas de violência doméstica. Também o Canadá tem indices altos. Alguns programas, como ações capazes de diminuir o machismo nas escolas, têm dado bons resultados, mas a médio e longo prazo.

3 Sobre esse assunto, ver ainda dados da Secretaria de Segurança Pública e Polícia Militar do Estado de São Paulo, publicados na Revista Veja, edição 1735, ano 35, n. 3, pp. $42-45$, de 22 de janeiro de 2002 . 
sob forte influência de governos militares antidemocráticos deixou a polícia militar enfraquecida em relação aos conhecimentos mais básicos sobre como lidar e se entender com a população em geral, sobretudo com as comunidades mais pobres e marginalizadas, para com elas manter a ordem pública.

Pergunta-se, agora, como fazer o policiamento? Qual a melhor forma de fazer policiamento? Existem outras formas de prevenir e combater a criminalidade? A polícia, tanto formalmente (pela sua direção, constituída pelo Estado) como informalmente (pelo comportamento dos praças e oficiais), procura uma aproximação com a universidade e com os centros de construção do saber em busca de respostas. Hoje, é comum encontrar policiais fardados circulando pelos corredores das universidades e presentes nas salas de aula.

Pergunta-se, agora, como fazer o policiamento? Qual a melhor forma de fazer policiamento? Existem outras formas de prevenir e combater a criminalidade? A polícia, tanto formalmente (pela sua direção, constituída pelo Estado) como informalmente (pelo comportamento dos praças e oficiais), procura uma aproximação com a universidade e com os centros de

construção do saber em busca de respostas.
Esse movimento pode ser interpretado como uma busca de novos saberes e conhecimentos. Convênios entre a polícia militar e instituições científicas são freqüentemente celebrados e noticiados pela mídia e as novas tecnologias de informação passam a ser largamente utilizadas. Buscam-se outras maneiras de abordar e de fazer segurança pública e praticar policiamento.

De acordo com Bittner (1975), a atividade policial pode ser concebida, basicamente, de duas formas distintas: o chamado modelo law-officer (polícia da lei ou legal) e o peace officer (polícia de paz).

No primeiro, a principal atividade da polícia seria o controle do crime. Os policiais orientam suas ações no sentido de prender e identificar culpados, coibir comportamentos desviantes e impor a ordem, de acordo com a lei. Agindo dessa forma, acreditam poder influenciar os resultados finais dos processos criminais. A perspectiva é fundamentalmente punitiva e a ação é sobre os desviantes e seus comportamentos. Esse modelo baseia-se em uma concepção de policiamento considerada reativa, ou seja, que espera a ocorrência do crime para entrar em ação. Embora tenha como mérito restringir a ação do Estado sobre a população, na medida em que a polícia intervém apenas quando é chamada, tem a limitação de não atuar sobre crimes contra instituições, como os de colarinho branco ou sem testemunhas, pois nesses casos não há chamados.

São inúmeras as evidências da falência desse modelo e diversas "pesquisas realizadas sobre organizações policiais desmitificam uma série de crenças a respeito da polícia, mostrando que, ao contrário do que os controle e prevenção de crimes" (Souza, 1999, p.

46). Moore (1992) também chama a atenção para esse tipo de policiamento que não valoriza as relações interpessoais com a comunidade. Trata-se, para ele, de um afastamento das pessoas que significa, também, um afastamento da realidade e traz como grave conseqüência o desconhecimento do contexto de problemas que se relacionam com a quebra da lei.

No segundo modelo, peace officer, o lado social da atividade policial é valorizado. A atividade não é mais voltada para a tipificação de pessoas suspeitas e criminosos e, o que é mais importante, preventivamente torna-se atenta aos riscos e ameaças à manutenção da ordem pública, partam essas ameaças do indivíduo, de grupos ou de situações. Nessa mesma linha, entende-se que a função dos peace officers consiste muito mais em reduzir "o total agregado de problemas numa determinada área do que em definir a autoria do crime" (Souza, 1999, p. 29). Policiais estariam, assim, envolvidos em atividades que não implicam propriamente a invocação das leis, mas tomariam decisões práticas, levando em conta as circunstâncias em que as solicitações são formuladas.

"Embora a organização policial não tenha estabelecido regras e formas de controle da atividade dos peace officers e não haja unanimidade entre seus membros em reconhecê-la como um trabalho tipicamente de polícia, o que a torna legítima como um domínio policial é a crença do público em geral na polícia para decidir situações que, mesmo não contendo nenhum aspecto criminal ou legal, implicam o uso de uma autoridade que, para a maioria das pessoas, só o policial possui" (Souza, 1999, p. 29).

Nesse ponto, chega-se à conclusão de que combater o crime não é a mesma coisa que ir à guerra e, assim, a desmilitarização das polícias tem sido uma tendência de significado democrático, bem-sucedida em muitos países. Articular-se com a comunidade, com outros agentes que zelam pelo bem-estar social, como postos de saúde, hospitais, escolas, associações de bairro, obtendo sua colaboração, parece ser um caminho mais acertado e exitoso para as polícias.

Como exemplo, pode-se citar a experiência realizada pela polícia do condado de Baltimore em Maryland, nos EUA, descrita por Skolnick e Bayley (2002). Em um programa denominado "policiamento orientado para o cidadão", um grupo especializado de policiais trabalhava com os policiais do patrulhamento de rotina "procurando localizar com precisão as condições existentes que não estavam respondendo à mobilização normal da patrulha (...). Nesse processo, eles analisaram os dados dos incidentes, conversaram exaustivamente com os 
moradores, fizeram visitas domicliares e exploraram a boa vontade de outras agências em ajudá-los" (p. 38). Percebeu-se que o furto de luvas de baseball era bastante comum numa determinada época do ano, e a simples criação de um programa de financiamento para famílias de baixa renda, para aquisição desse bem, fez cair drasticamente esse tipo de ocorrência.

Em outros casos, a colocação de semáforos em determinadas esquinas e a presença de guardas de trânsito possibilitou a solução de problemas dos moradores, melhoria da ordem pública e ganhos no equacionamento do trabalho de vigilância do bairro.

Em muitas situações, não existe propriamente um criminoso, mas um conflito social ou insatisfações sobre as quais a polícia vai atuar como solucionadora de problemas, mediadora e negociadora de acordos, buscando, portanto, um reequilíbrio social. A ação é de pacificação e tranqüilização. A perspectiva é mais negociadora e menos punitiva. Trata-se de resolução de problemas e conflitos em que a atuação do policial está mais próxima da de um agente de transformação social. A desordem, como sugere Wilson (1983), é um sinal de enfraquecimento de controles informais que a comunidade exerce sobre seus membros e se, percebendo isso, ela chama a polícia para ajudála, é porque reconhece uma autoridade competente. E essa demanda não pode deixar de ser adequadamente respondida.

Essa concepção de ação policial, como veremos, está de acordo com as idéias de Becker (1977), segundo as quais poucas regras são consensuais e os grupos sociais criam os desvios ao estabelecerem regras para resolver seus problemas. Assim, a ordem social é um equilíbrio precário, que deve ser constantemente revisto e reconstituído pelos atores sociais, produto de negociações, de diplomacia, de barganha e de processos do tipo "toma lá, dá cá".

Sabemos que esse novo modelo de atuação implica profunda mudança no interior das organizações policiais, sobretudo em termos de descentralização das decisões, maior autonomia para os agentes e redefinição do papel da polícia, que estaria, assim, muito mais a serviço da população que do Estado. Trata-se, portanto, de uma mudança na cultura organizacional. A nosso ver, toda a política de gestão de recursos humanos teria de ser reorientada, sobretudo em termos de treinamento e qualificação profissional, mas também de seleção e avaliação de desempenho. Novas habilidades entram em jogo, como dialogar, argumentar e interagir com as comunidades, além de novas formas de pensar a criminalidade e suas causas. $\mathrm{O}$ uso da violência e da força seria substituído pela ação inteligente e habilidosa. Nesse sentido, iniciativas produzidas com base em pesquisas de natureza científica e análise de informações sobre os eventos, envolvendo cooperação entre universidades e polícias, têm levado a alguns resultados animadores.

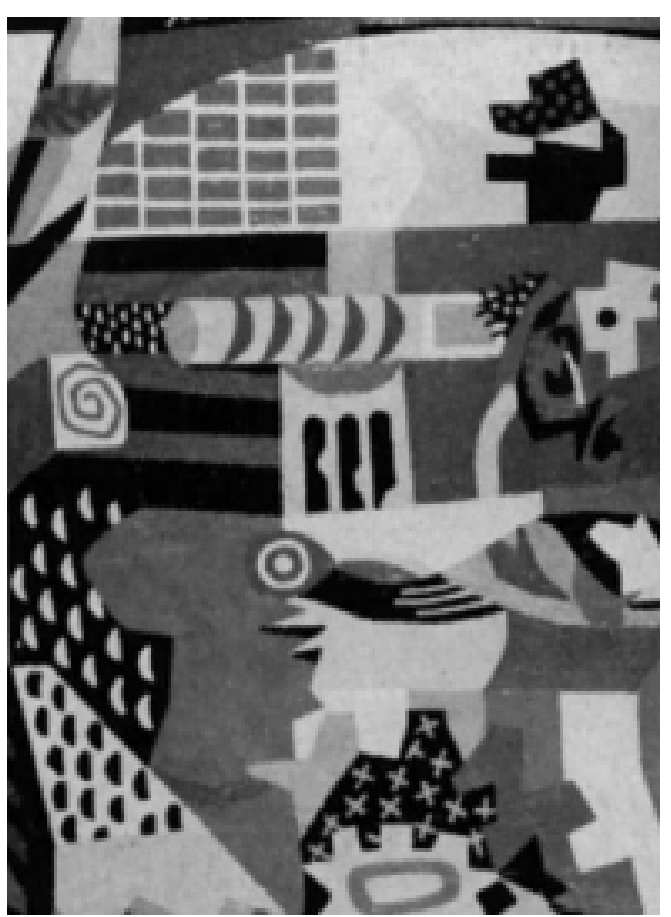

Ao contrário dos estereótipos que apresentam o policial como um profissional constantemente envolvido com homicídios, armas, tiros, crimese violência, descobriuse que, na maior parte do tempo, ele atende a demandas de cunho assistencial e resolve problemas que exigem negociação com pessoas, grupose com a comunidade .

Bittner \& Bayley

Na realidade, a análise das atividades dos policiais revelou nosso profundo desconhecimento dessa profissão. Ao contrário dos estereótipos que apresentam o policial como um profissional constantemente envolvido com homicídios, armas, tiros, crimes e violência, descobriu-se que, na maior parte do tempo, ele atende a demandas de cunho assistencial e resolve problemas que exigem negociação com pessoas, grupos e com a comunidade (Bittner, 1990, Bayley, 1994, Beato, 1999). Por exemplo: ajudar pessoas alcoolizadas, apartar brigas de família e rixas entre vizinhos, socorrer vítimas de acidentes e doentes mentais, retirar animais das vias públicas, recolher mendigos, atender parturientes etc. Segundo os pesquisadores, há uma "falácia dramática" muito explorada pela mídia, pois o envolvimento com delitos criminais não chega a representar $15 \%$ do tempo efetivo de trabalho da polícia.

Uma polícia descentralizada e comunitariamente orientada, ao estabelecer um contato mais estreito e intenso com a população, legitima seu trabalho e, além disso, reduz o "temor da criminalidade", fator muito importante para a qualidade de vida de uma população. Agindo assim, proativamente, a polícia pode levantar dados e informações relevantes e, 
baseando-se nestes, orientar seus esforços: onde estão ocorrendo os problemas? Com que freqüência? Qual a natureza desses problemas? Onde posicionar os policiais? Quais ações são mais efetivas? Quais são os grupos-chave na comunidade? Como trocar informações com eles e produzir conhecimentos sobre essa realidade? Aqui, a produção e a organização das informações têm papel decisivo.

Sabe-se, por exemplo, que a presença de testemunhas e sua efetiva disposição de colaborar é fator decisivo para a elucidação de crimes e conseqüente prisão de criminosos. $O$ trabalho investigativo é, portanto, altamente dependente de testemunhas, cuja colaboração varia, evidentemente, conforme o grau de confiança que têm na polícia.

4 Sobre esse assunto, ver também entrevista com o sociólogo Glaucio Ary Dillon Soares, estudioso da violência na América Latina e professor titular da Universidade da Flórida, publicada na Revista Veja de 16 de agosto de 2000.

5 A teoria dos rótulos de Ernest Becker foi fortemente influenciada pelo chamado interacionismo simbólico de George Herbert Mead, cujas idéias são profundamente inovadoras na Psicologia, na medida em que, sem negar a existência de um self, concebemno como um processo, e não como uma estrutura. Blumer (1980), estudioso de Mead (1972) e criador do termo "interacionismo simbólico", observa que se têm ali três premissas básicas: (a) os seres humanos agem em relação ao mundo fundamentando-se nos significados que este lhes oferece; (b) os significados dos elementos - objetos físicos, pessoas, instituições etc. provêm da interação entre as pessoas, ou seja, "para um indivíduo, o significado de um elemento nasce da maneira como outras pessoas agem em relação a si no tocante ao elemento" ( $p$. 121) e (c) os elementos são modificados por um processo interpretativo utilizado pela pessoa ao se relacionar com eles. Os significados são, assim, produtos sociais determinados pelas atividades humanas em um processo de interação social. Farr (1998) considera o interacionismo simbólico como uma forma sociológica de Psicologia Social.
Essa reflexão sobre a natureza do trabalho policial em sociedades democráticas nos leva a discutir também as formas de pensar a criminalidade. Que modelos teóricos sustentam o modelo de polícia comunitariamente orientado? Na realidade, são eles que estão na base das diversas ações que visam a combater ou diminuir o fenômeno.

Pode-se conceber duas grandes perspectivas teóricas básicas na sociologia da criminalidade: as chamadas teorias culturalistas, que concebem a criminalidade como produto do sistema social e, portanto, como uma disfunção social, e as chamadas teorias racionalistas, que vêem o crime como uma atividade rotineira e normal, necessária e produzida pela própria sociedade.

Das teorias culturalistas deriva uma série de políticas públicas destinadas a reduzir a criminalidade atacando suas possíveis causas, ou seja, a pobreza, o desemprego, a falta de escolas e de oportunidades etc. Das teorias racionalistas nasce uma outra estratégia de combate à criminalidade, segundo a qual o principal papel do Estado consiste em dissuadir o criminoso, um tomador racional de decisões, da prática de delitos.

O principal problema das chamadas abordagens culturalistas, principalmente estruturalistasfuncionalistas e marxistas, é determinar ações que não têm reduzido efetivamente as taxas de criminalidade. Na realidade, não têm sido empiricamente confirmadas. Diversos estudos têm mostrado, por exemplo, que redução de desemprego, crescimento econômico e aumento da escolaridade não têm efeito redutor sobre as taxas de criminalidade nas grandes cidades (Sapori e Wanderley, 2001). De fato, a melhoria desses indicadores é altamente desejável, mas não podemos esperar mudanças econômicas, sociais e políticas para depois combater a criminalidade. ${ }^{4}$
Procurando relacionar crime e violência urbana com a construção e a consolidação da democracia no Brasil, Paixão (1988) refere-se a uma crença muito comum, na realidade uma hipótese infundada, que associa a pobreza a criminalidade. Essa tese, que tem forte apelo ideológico, não explica, entre outras coisas, porque a imensa maioria dos pobres urbanos opta pela adoção de padrões normais de comportamento e repudia moralmente a criminalidade. $O$ autor sustenta que há, muito mais, uma vulnerabilidade dos pobres frente ao sistema de justiça criminal e, muito menos, uma suposta tendência ou motivação criminosa imposta por sua condição social.

Nessa direção, ganha corpo a hipótese de que, paradoxalmente, as teorias que percebem o crime como atividade rotineira e normal colaboram de maneira mais direta para a adoção de modelos mais democráticos de atuação policial. Justamente porque não estão voltadas para o criminoso, mas para os contextos em que o crime se desenvolve, as teorias racionalistas acabam fornecendo bases para o desenvolvimento de políticas públicas mais articuladas com a promoção da cidadania, sobretudo junto às populações economicamente carentes. Essas teorias têm o mérito de desindividualizar, despersonalizar, despsicologizar e despatologizar a questão da criminalidade.

A meu ver, tudo começa com o já citado Becker (1977) e sua teoria dos rótulos ${ }^{5}$, quando afirma:

"Todos os grupos sociais fazem regras e tentam, em alguns momentos e em algumas circunstâncias, fazer com que elas sejam seguidas. (...) Quando uma regra é imposta, a pessoa que se supõe tê-la transgredido pode ser vista como um tipo especial de pessoa, alguém que não se espera que viva segundo as regras com as quais o grupo concorda. Ela é vista como marginal ou desviante. Mas a pessoa que recebe o rótulo de marginal pode ter uma visão diferente da questão. Ela pode não aceitar a regra em função da qual está sendo julgada e pode não considerar aqueles que a julgam como competentes ou legitimamente autorizados para julgá-la. Conseqüentemente, surge um segundo significado do termo: a pessoa que quebra as regras pode sentir que seus juízes são desviantes" (Becker, 1977, p. 49).

O autor não vê situações de vida ou questões de personalidade que possam explicar o desvio, pois o fato de um ato ser considerado desviante é posterior à sua ocorrência e depende de como as pessoas reagem a ele. Na sociedade, há vários grupos e regras que entram em conflito e se contradizem e, quase sempre, haverá discordâncias sobre o que é mais conveniente em uma dada situação. Temos, portanto, que as regras não são universalmente aceitas e que a ordem social é produto de 
negociações, acordos e barganhas, em um processo essencialmente político.

"Desse ponto de vista, o desvio não é uma qualidade do ato que a pessoa comete, mas uma conseqüência da aplicação, por outras pessoas, de regras e sanções a um transgressor. O desviante é alguém a quem aquele rótulo foi aplicado com sucesso; comportamento desviante é aquele que as pessoas rotulam como tal" (Becker,1977, p. 60).

De fato, Paixão (1988) enfatiza o aporte da microssociologia para a teoria social, notadamente do interacionismo simbólico e da etnometodologia, pois podem contribuir para a rediscussão das relações entre marginalidade e criminalidade, resgatando a "dimensão política envolvida na aplicação das regras legais à periferia social" (p.173). Sem negar a ambigüidade dos mais pobres em relação à polícia, lembra Thompson e faz referência à desconfiança histórica das classes populares para com a organização policial devido à "imposição de modelos de convivência e resolução de conflitos externos à comunidade e utilizados por outros contra ela" (p.178).

Becker (1977) criou o "modelo seqüencial do desvio", identificando quatro tipos de comportamento desviante:

OTipo conformista (não desviante) - o indivíduo tem um comportamento obediente e é percebido como tal pelos outros.

- Tipo desviante puro - o indivíduo tem um comportamento "quebra-regras" e é percebido como tal pelos outros.

- Tipo falsamente acusado - o indivíduo tem um comportamento obediente, mas é percebido como desviante pelos outros.

-Tipo desviante secreto - o indivíduo tem um comportamento "quebra-regras", mas não é percebido como desviante pelos outros.

Voltando-se sobretudo para os "falsamente acusados", o autor adota a idéia de "carreira desviante" e explora aquilo que chamou de "primeiro passo", ou seja, muitos atos não conformistas foram cometidos por pessoas profundamente mergulhadas numa subcultura particular e que não tiveram nenhuma intenção de opor-se às regras estabelecidas pelo grupo majoritário ou prevalente. Os habitantes do norte do México, por exemplo, consideravam, por sua cultura, perfeitamente normal fumar "marijuana", mas foram presos pela polícia americana quando os Estados Unidos ocuparam aquela região.

O fato de ser apanhado e publicamente rotulado como desviante é, para Becker (1977), um passo decisivo na fixação dos indivíduos num padrão estável de comportamento marginal ou marginalizante. Isso porque, posteriormente, sãoIhes negados meios de prosseguir na vida através das rotinas comuns. $O$ passo final seria a adesão a um grupo desviante, no qual o indivíduo vai encontrar apoio emocional, racionalizações ideológicas e, sobretudo, aprender a prosseguir em seu curso desviante com um mínimo de problemas.

Temos, portanto, uma crítica às teorias sociológicas e psicológicas que pretendem estudar as motivações "doentias" dos "desviantes", considerando que todos o somos muito mais do que parecemos e temos motivações muito semelhantes. Essa crítica sugere que é melhor estudar porque as pessoas convencionais não levam até o fim seus impulsos desviantes. Nessa perspectiva, ou seja, da normalidade do crime, a teoria dos rótulos de Becker (1977) fomentou um tipo de discussão que, contribuindo para desmitificar e, de certa forma, banalizar o desvio, abriu caminho para a formulação de novos modelos explicativos: as teorias que atentam para a racionalidade dos criminosos em um conjunto articulado de idéias que podemos reunir sob a denominação genérica de "teoria das oportunidades".

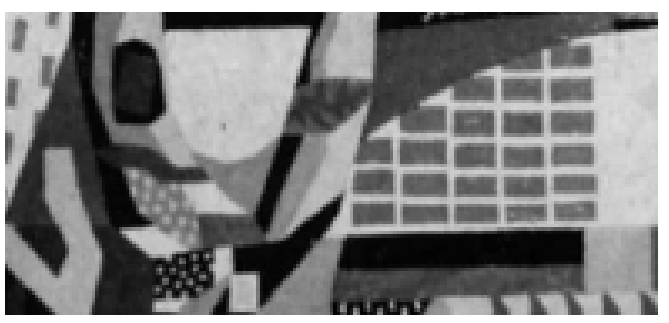

Essa perspectiva, além de considerar que os desviantes têm motivações muito semelhantes às das pessoas normais, enfatiza que a conduta criminal se guia pelas mesmas pautas de racionalidade que orientam a conduta socialmente legítima. Assim, a decisão de executar um crime dependeria da probabilidade de que este redundasse em benefício superior aos custos e riscos envolvidos, entre os quais o mais significativo seria a possibilidade de ser descoberto e enviado à prisão.

Há uma clara preocupação com os aspectos aplicados da criminologia, no sentido da formulação de políticas e programas de prevenção e controle do crime, voltados, portanto, para a solução mais imediata dos problemas da criminalidade e tendo efeito direto, por exemplo, na redução das taxas de criminalidade nas grandes cidades. O elemento teórico comum é o da deliberação racional dos indivíduos quanto à criminalidade, que seria, assim, uma escolha compensadora. Considera-se, ainda, que os
"Todos os grupos sociais fazem regras $\Theta$ tentam, em alguns momentos e em algumas circunstâncias, fazer com que elas sejam seguidas. (...) Quando uma regra é imposta, a pessoa que se supõe tê-la transgredido pode ser vista como um tipo especial de pessoa, alguém que não se espera que viva segundo as regras com as quais o grupo concorda. Ela é vista como marginal ou desviante".

Becker

6 Políticos burocratas autoridades corruptas, nos chamados crimes de colarinho branco, que não estamos discutindo diretamente aqui, podem, freqüentemente, ser enquadrados nessa categoria.

7 Teoria do espaço defensivo Newman; teoria das atividades rotineiras - Felson e Cohen; teoria da escolha racional aplicada ao crime - Newman e opp; prevenção situacional de crimes-Clark. 
criminosos podem ser dissuadidos ou desencorajados do crime.

Há tentativas interessantes de redução das oportunidades de crime através de medidas que associam arranjos arquitetônicos com mudança de comportamento da comunidade. Trata-se de condições ambientais, de espaço e construções que dificultem e desestimulem o trabalho de ofensores, possibilitando um maior controle e vigilância pela própria população sobre as casas e edifícios. Sabe-se que a manutenção de ruas, calçadas, paredes e muros limpos, os cuidados com o ambiente físico, de modo geral, têm correlação positiva com a queda da criminalidade em muitos locais. ${ }^{8}$

"A idéia não é reformar indivíduos, o que é extremamente dificil, mas dificultar a ocorrência de crimes"

Beato Filho

8 A redução de crimes em favelas com ruelas muito apertadas que facilitam a fuga de ofensores pode ser; muitas vezes, obtida apenas com reformas urbanisticas relativamente simples, que alterem a arquitetura local.

9 Melhor do que pensar em criminalidade como fenômeno homogênio seria falar em criminalidades, ou seja, vários tipos de crime, para os quais as explicações causais seriam diferentes, mas o aprofundamento dessa discussão caberia em um outro trabalho.
A construção de grandes prédios de habitação coletiva, cujos moradores mal se conhecem e em que existem numerosos acessos não controlados, que facilitam a ação de predadores, faz com que as pessoas percam aquilo que alguns urbanistas chegaram a chamar de instinto natural de "territorialidade". Soluções arquitetônicas de recuperação de moradias públicas que procuram estimular seus moradores a exercer essa "territorialidade" relacionam-se com a idéia de "espaço defensivo". Trata-se de reduzir o anonimato e promover a vigilância natural, ou seja, dos próprios moradores, bem como de reduzir as vias de escape para ofensores potenciais.

A abordagem das "atividades rotineiras" busca explicar a evolução das taxas de crime através das circunstâncias em que ocorrem. Desse ponto de vista, para que um ato predatório ocorra, seria necessária a convergência, no tempo e no espaço, de três elementos ou condições (Cohen e Felson, 1979, citado por Sapori e Wanderley, 2001, p. 48):

Um ofensor motivado. Alguém predisposto a cometer um delito.

Um alvo disponível. Uma pessoa ou um objeto que possa ser atacado.

Ausência de guardiães capazes de impedir a violação.

A "prevenção situacional de crimes", muito utilizada atualmente, toma como base a "teoria das atividades rotineiras" e um conjunto de técnicas para a redução da criminalidade. Consiste em aumentar o esforço necessário para se cometer um crime, incrementando-se dificuldades e riscos percebidos pelos possíveis agressores, desenvolvendo-se e mantendo-se um ambiente com regras claras e bem definidas, removendo-se possíveis desculpas e possibilidades de mal-entendidos.
A ênfase recai sobre a conjunção de fatores ambientais e temporais que criariam "oportunidades", e é isso que precisa ser evitado. "A idéia não é reformar indivíduos, o que é extremamente difícil, mas dificultar a ocorrência de crimes" (Beato Filho, 1999, p. 24). Pesquisas mostram que muitos desviantes não saem de casa já com a intenção de roubar. Na verdade, o crime ordinário acontece regularmente em alguma situação e é sobre essa situação que se deve estabelecer controle. Por exemplo, o aumento de arrombamentos residenciais correlaciona-se com mudanças na estrutura de empregos da sociedade: um maior número de pessoas, incluindo mulheres, abandona a casa para trabalhar, deixando-a mais vulnerável às atividades predatórias.

A chamada "análise econômica dos crimes" defende a idéia de que os indivíduos, criminosos ou não, são ativos tomadores de decisões racionais que respondem a incentivos e custos associados às suas ações. Entende-se que a atratividade da via criminosa é tanto maior quantos forem os seus ganhos materiais, psíquicos e simbólicos, quando comparados com os benefícios do trabalho e outros meios legítimos de satisfação dos interesses humanos. Assim, o indivíduo avalia se o crime compensa, se o beneficio do crime na produção de renda, prestígio, poder e/ou emoção é maior que os riscos ou custos de uma possível punição.

Não obstante a importância dos modelos econômicos, sobretudo por desmitificarem e chamarem a atenção para a banalidade e a natureza rotineira do crime, receberam severas críticas por serem insensíveis a determinadas formas de crimes, sobretudo os chamados crimes passionais, e por não perceberem a complexidade do fenômeno nas sociedades modernas. Diz-se também que o modelo de mercado não se ajusta a muitos crimes ordinários, pois, embora existam inúmeras vítimas, não há muita "demanda" de pessoas dispostas a serem atacadas. Isso seria absurdo.

Entretanto, sem negligenciar a complexidade e a sutileza do tema da criminalidade ${ }^{9}$ o que se pretende aqui é alertar para a delicadeza do problema do "primeiro passo". Não seria, quase sempre, uma questão de oportunidade? A situação não seria, muitas vezes, fortemente agravada pelo processo de rotulação? Se respondemos afirmativamente a questões desse tipo, faz-se necessário rever o papel e a responsabilidade das polícias, do Estado, da comunidade e, particularmente, dos psicólogos, no sentido de evitar e/ou interromper carreiras criminosas, impedindo a rotulação pública daqueles que ainda não são, mas podem se tornar verdadeiramente criminosos, justamente em função do tratamento recebido por parte das autoridades, da comunidade e dos profissionais que os atendem. 
BAYLEY, D. H. Police for the future. New York: Oxford University Press, 1994

BEATO FILHO, C. C. Determinantes da Criminalidade em Minas Gerais Revista Brasileira de Ciências Sociais, v.13, n. 37, 1998, pp. 74-89.

Ação e Estratégia das Organizações Policiais. Belo Horizonte: Departamento de Sociologia e Antropologia, UFMG 1999.

Fontes de Dados Policiais em Estudos Criminológicos: Limites e Potenciais..www.est.ufmg.br/crisp, s/d.

BEATO FILHO, C. C.; BATTUCCI, E.; ESPÍRITOSANTO, L. E.; SAPOR L. F.; SANTOS, M. A. C.; MORAIS, P.C. C.; ASSUNÇÃO, R. e SILVA, S. L. F. Criminalidade violenta em Minas Gerais - 1986 a 1997. www.est.ufmg.br/crisp, 2000.

BECKER, H. S. Uma Teoria da Ação Coletiva. Rio de Janeiro: Zahar Editores, 1997

BITTNER, E. The Functions of Police in Modern Society. New York: Jason Aronson, 1975.

Aspects of the Police Work. Boston: Northeastern University Press, 1990.

BLUMER, H. A Natureza do Interacionismo Simbólico. In: Mortensen, C. David (Org.). Teoria da comunicação: textos básicos. São Paulo: Mosaico, 1980, pp.119-138.
FARR, R. M. As Raízes da Psicologia Social Moderna (1872-1954). Petrópolis: Vozes, 1988

GONTIJO, R. F. Sistema Integrado de Gestão de Informações de Segurança Pública do Estado de Minas Gerais. Monografia, Polícia Militar de Minas Gerais, Belo Horizonte, 2000.

MEAD, G. H. Espiritu, Persona y Sociedad. Buenos Aires: Editorial Paidos (originalmente publicado em 1934), 1972.

MOORE, M. H. Problem-solving Community Policing. Chicago: The University of Chicago, 1992

PAIXÃO, L. A. Crime, Controle Social e Consolidação da Democracia: as Metáforas da Cidadania. In: Reis, F. W. e O'Donnell, G. (Org.). A Democracia no Brasil: Dilemas e Perspectivas. São Paulo: Vértice, Editora Revista dos Tribunais, 1988, pp. 168-199.

SAPORI L. F. e WANDERIEY, C. B. A Relação entre o Desemprego e a Violência na Sociedade Brasileira: entre o Mito e a Realidade. Em: Cadernos de Adenauer II - A Violência do cotidiano. São Paulo: Fundação Konrad Adenauer, 2001, pp. 43-73.

SKOLNICK, J. H. e BAYLEY, D. H. Policiamento Comunitário: Questões e Práticas através do Mundo. São Paulo: Editora da USP, 2002.

SOUZA, E. Policiamento Comunitário em Belo Horizonte. Dissertação de Mestrado, Universidade Federal de Minas Gerais, Belo Horizonte, 1999.

Referências

WILSON, J. Q. Thinking about Crime. New York: Vintage Books, 1983. 